\title{
PROBING REDUCING POWER FOR FERRYL PHYTOGLOBINS OF SEVERAL PHENOLIC COMPOUNDS USING THEIR KINETIC PROFILES ASSISTED BY CHEMOMETRIC METHODS
}

\author{
GALABA NAUMOVA-LEȚIA ${ }^{\mathrm{a}}$, AUGUSTIN C. MOȚ ${ }^{\mathrm{a}^{*}}$
}

\begin{abstract}
Several phenolic compounds belonging to different classes were comparatively analyzed for their ability to reduce ferryl forms of three non-symbiotic phytoglobins which were generated in situ by hydrogen peroxide and thus acting as enzymes. The kinetic profiles of the substrates oxidation were evaluated using principal component analysis and cluster analysis. The three globins were different not only in terms of rate but also in mechanism and the electron donor ability of the studied phenolics were strongly enzyme specific and did not depend only upon their chemical structure but also upon assumptive binding pocket environment.
\end{abstract}

Keywords: phenolics, flavonoids, phytoglobin, reducing power

\section{INTRODUCTION}

Natural phenolic compounds constitute a broad group of phytochemicals with various physiological and biochemical activity. They form one of the largest classes of secondary plant metabolites which act effectively against different abiotic and biotic stresses in plants. Phenolic compounds are produced within two metabolic pathways: acetate/malonate pathway in which

\footnotetext{
a Babeş-Bolyai University, Faculty of Chemistry and Chemical Engineering, 11 Arany Janos str., RO-400028, Cluj-Napoca, Romania

*Corresponding author: augustinmot@chem.ubbcluj.ro
} 
simple phenols are produced and shikimate/phenylpropanoid pathway that leads to phenylpropanoids or combination of the both pathways, resulting in formation of flavonoids, one of the most abundant phenolic classes in nature. Some phenolic compounds are widely distributed in the plant kingdom while others can be found in specific plant families, specific plant organelles or only at certain phase of the plant developing tissues [1-3].

Phenolic compounds can be classified in different ways: distribution in nature, form and location in plants (insoluble - bound into stable complexes with biomolecules of the cell wall or soluble - free, not bound fractions). One of the most accepted and general classification is based on the basic carbon skeleton which categorized them in couple main classes such as simple phenols, phenolic acids and analogs, chalcones, coumarins, stilbenes, flavonoids, lignans, lignins and others $[1,4]$. Due to the large diversity of structures and properties, phenolic compounds possess variety of different functions in the plants starting with involvement in the growth of the plant to plant reproduction and participation in defense mechanisms. Phenolic compounds can act as visual signals for attracting pollinating insects, phytoalexins, photoreceptors, detoxifying agents, scavenger of reactive oxygen species (ROS) such as $\mathrm{H}_{2} \mathrm{O}_{2}$, hydroxyl, peroxyl or alkoxyl radical; they also, contribute to different flavours and colour shades in flowers, leaves, fruits and vegetables, protect the plant cells against UV radiation, fungal, bacterium or virus pathogens, parasites and herbivores, etc. [5-12].

Phenolic acids include two subclasses: hydroxybenzoic acids (e.g. vanillic acid, gallic acid, protocatechuic acid etc.) with $\mathrm{C}_{6}-\mathrm{C}_{1}$ structure and hydroxycinnamic acids (e.g. caffeic acid, p-coumaric acid, ferulic acid etc.) with $\mathrm{C}_{6}-\mathrm{C}_{3}$ structure. Phenolic acids naturally occur in free form or conjugate esters or amides [13]. Stilbenoids (stilbenes) are phenylpropanoids belonging to the family of phenolic compounds with $\mathrm{C}_{6}-\mathrm{C}_{2}-\mathrm{C}_{6}$ structure (two aromatic rings connected with ethane bridge). Stilbenoids are hydroxylated derivatives of stilbene and they are not present in all plant species, due to limited stilbene synthase genes expression, but their distribution is rather heterogonous through the plant kingdom. The natural stilbenoids exist in monomeric or oligomeric form (e.g. trans-resveratrol) or frequently as glycosylated form with different substitution $[13,14]$. Coumarins $(2 H$-chromen-2-one) are natural compounds belonging to the group of lactones with $\mathrm{C}_{6}-\mathrm{C}_{3}$ rich electron conjugated system with a charge transport properties. Coumarins are synthesised with hydroxylation, isomerization, glycolysis and cyclization of cinnamic acid and naturally in plants are present in free form, but most often as glycosides (e.g. aesculetin) $[1,13,15,16]$.

Flavonoids (or bioflavonoids) are extensively distributed in green plant kingdom. Flavonoids are present in all part of the plants, especially the photosynthesising plant cells of a wide range of vascular plants; up to date 
over 8000 flavonoid compounds have been identified and the number is still increasing. Chemically, they all have characteristic $\mathrm{C}_{6}-\mathrm{C}_{3}-\mathrm{C}_{6}$ benzo- $\gamma$-pyrone skeleton consists of two benzene rings ( $A$ and $B$, Table 1 ) connected through heterocyclic pyran ring $(C)[5,6,8,17]$. Flavonoids generally, occur in plants as glycosides (O-glycoside or C-glycoside) with a monosaccharide or disaccharide attached, but also as aglycones or methylated and sulfated derivatives $[9,11]$. Flavonoids can be divided into several classes based on the structure of the carbon skeleton, substitution, conjugation, degree of hydroxylation and degree of polymerization such as, flavones, flavonols, flavanones, flavanols, isoflavones, flavanonols and anthocyanidins $[5,8,18]$. UV-Vis spectral features of flavonoids display two major absorption bands in the region from $200-400 \mathrm{~nm}$, which are known as band I (300-385 $\mathrm{nm})$ and band II $(250-285 \mathrm{~nm})[9,19,20]$. The substitution of functional groups in the flavonoid skeleton can cause shift in absorption maximum. The radical scavenging activity of the flavonoids is in connected with the chemical structure and type of substituents of the $B$ and $C$ rings; meaning that the greater the number of hydroxyl groups in ring $B$, the lower the redox potential and the stronger the reducing power [21]. In general, flavonoids with catechol moiety on ring $B\left(0.23<E_{p, a}<0.75 \mathrm{~V}\right)$ will be highly active and better antioxidant agents, than non-catechol derivatives $\left(E_{p, a}>0.8 \mathrm{~V}\right)$ $[5,12,22]$.

Hemoglobins (Hbs) are a large family of globular proteins found in all kingdoms of life with various biological functions such as oxygen transport and storage, electron transfer, $\mathrm{O}_{2}, \mathrm{NO}$ and $\mathrm{CO}$ sensing and redox catalysis [23-26]. Nonsymbiotic plant hemoglobins (nsHbs) are divided in three different classes (class 1, class 2 and class 3 or truncated $\mathrm{Hb}$ ) based on oxygen affinity and structural features [27-29]. Similar to all Hbs, nsHbs are involved in ROS and RNS involving pathways, exhibiting nitrite reductase activity, peroxidases activity and are capable of NO scavenging under hypoxic stress [24,26,30-32]. The highly reactive ferryl species $\left[\mathrm{Fe}^{4+}=\mathrm{O}^{2-}\right]^{2+}$ can be formed due to abiotic or biotic stresses under different physiological conditions in reaction of the hemoglobins with hydrogen peroxide $\left(\mathrm{H}_{2} \mathrm{O}_{2}\right)[33,34]$. The phenolic compounds, especially flavonoids have ability to scavenge ferryl hemoglobin [35]. Both ferryl heme and the protein radical are very reactive species, which can induce oxidation of the biomolecules and cause tissue damage $[33,36]$.

Phenolic compounds under some stress conditions can exhibit prooxidant activity, which was previously reported [37]. The effects on some flavonoids (rutin, quercetin, (+)-catechin, luteolin, kaempferol, apigenin, genistein, (-)-epigallocatechin gallate, hesperetin) on the redox reaction, reducing ability, mechanisms, transportation, distribution, binding sites to human or bovine hemoglobin at physiological $\mathrm{pH}$ or acidic $\mathrm{pH}$ were investigated using different 
techniques like fluorescence spectroscopy, circular dichroism (CD), UV-Vis absorption spectroscopy, molecular modelling and Western blotting [34,38-42]. In general, phytophenolic compounds are well known for their antioxidant activity and act protective towards the oxidative damage in vitro and in vivo. Transportation, distribution, physiological and biochemical action of phenolic compounds is connected with important globular proteins [39] and lipid bilayer [43] interactions which makes them important besides their antioxidant capacity.

\section{RESULTS AND DISCUSSION}

Thirteen phenolic compounds were used in our study and their reducing powers towards the three different classes ferryl phytoglobins from Arabidopsis thaliana were investigated. Their chemical structures of the studied compounds, together with their classification are shown in Table 1. The ferryl species of the studied Hbs were generated in situ by hydrogen peroxide oxidation of the ferric form. These species are thought to be responsible electron subtraction from the phenolic compounds, oxidizing them while the ferryl is reduced back to the ferric form and reenters the catalytic cycle. Therefore, the studied Hbs served as enzymes (used in catalytic amounts) that oxidized the phenolic compounds coupled with peroxide reduction to water. The kinetic profiles of the phenolic compounds oxidation were monitored and a comparative analysis of their ferryl reducing power was employed using two chemometric methods, principal component analysis (PCA) and cluster analysis.

The studied phenolic compounds belong to two large classes (flavonoids and phenolic acids) including one representative from coumarins (aesculetin) and stilbenes (resveratrol) classes. In this study, the flavone (luteolin and apigenin), flavonol (quercetin, rutin and isoquercitrin) and flavanols (catechin and epicatechin) subclasses were part of the flavonoid class. Phenolic acids, as mentioned above are categorized here into two major subclasses, hydroxybenzoic acids and hydroxycinnamic acids; in our study we used vanillic acid, belonging to the first subclass and caffeic, ferulic and $p$-coumaric acids representatives from the second subclass (Table 1). 
Table 1. Chemical structural details of the studied phenolic compounds and their classification based on them, together with the working wavelength in their UV-vis spectrum (maximum peak). Color codes are kept the same during the study.

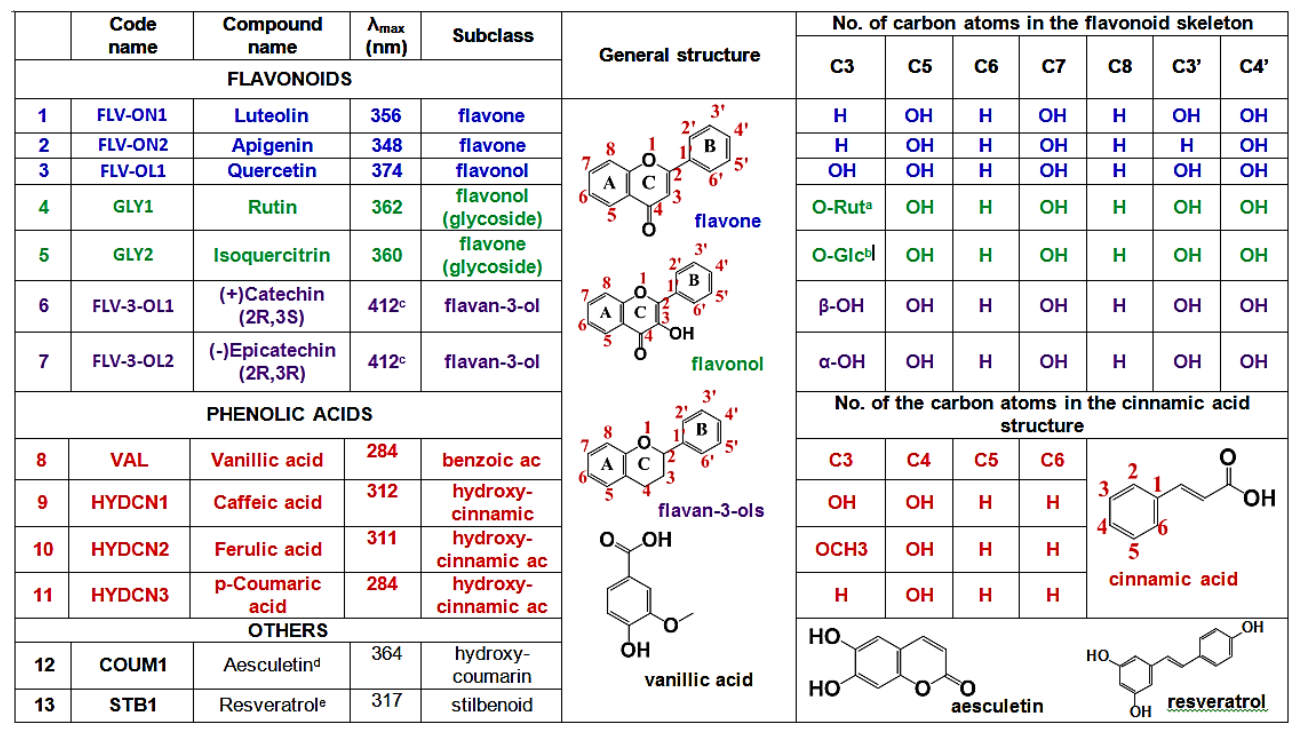

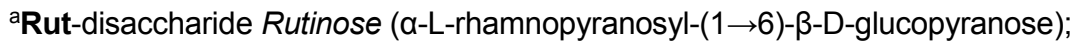

${ }^{b}$ Glc-monosaccharide D-Glucose ( $\beta$-D-glucopyranose); ' wavelength of the maximum peak of reaction product. ${ }^{\mathrm{d}}$ Aesculetin (6,7-dihydroxycoumarin) ${ }^{\text {e }}$ Resvertarol (3,5,4'-trihydroxystilbe

The typical spectral changes of four phenolic compounds (luteolin, quercetin, resveratrol and epicatechin), belonging to different classes and subclasses, in the presence of $\mathrm{H}_{2} \mathrm{O}_{2}$ and one of the three phytoglobins are shown on Figure 1. The UV-vis spectra features, including the extinction coefficients and position of maxima of the spectra are specific for each compound with more or less similarities, depending of their chemical structures. In the case of luteolin and quercetin (Figure 1A, B) the starting spectra have two salient absorption bands, as previously described, band I and band II. The absence of a 3-hydroxyl group in flavones differentiate them from flavonols, so the band I is always absorbing at a lower wavelength by $20-40 \mathrm{~nm}$ in contrast to the absorption maximum of flavonols [9,44]. In our case the flavonol quercetin displays a maximum absorbance at $374 \mathrm{~nm}$ in contrast to the flavone luteolin with maximum absorbance at $356 \mathrm{~nm}$, (all the maximum absorbances are given in Table 1). In the case of quercetin the reaction could be tracked by shifting of the maximum absorbance and appearing 
of new maximum absorbance at $334 \mathrm{~nm}$, characteristic for generating oxidized form of quercetin (quinone form), while in the case of luteolin the reaction could be tracked by the decrease of the typical band I $(356 \mathrm{~nm})$, due to the consumption of the luteolin during the reaction with the ferryl $\mathrm{Hb}$. The stilbenoid resveratrol (Figure1C) is having three maximum absorbances, one below $220 \mathrm{~nm}$ and two very close to each other $(307 \mathrm{~nm}$ and $317 \mathrm{~nm})$. The reaction is followed by the decrease of these bands, but appearing of a new band at $252 \mathrm{~nm}$ and a shoulder around $375 \mathrm{~nm}$, probably with some interferences of the $\mathrm{Hb}$ contribution around $405 \mathrm{~nm}$.

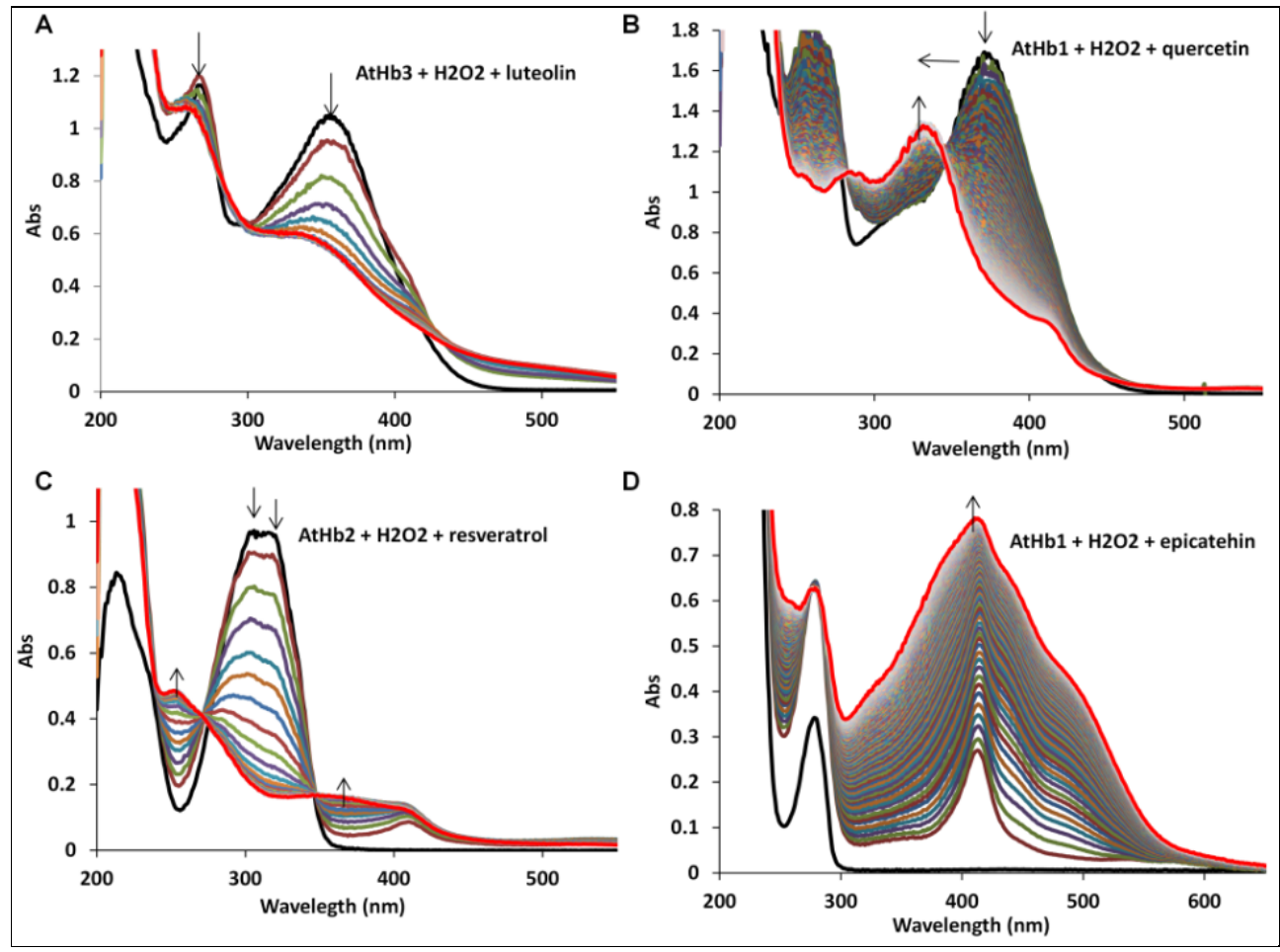

Figure 1. Reaction between the phenolic compounds and $A$. thaliana non-symbiotic hemoglobins in the presence of hydrogen peroxide $\left(\mathrm{H}_{2} \mathrm{O}_{2}\right)$. UV-Vis spectra changes of phytophenolic substrates oxidation in $50 \mathrm{mM}$ phosphate buffer $\mathrm{pH} 7$ and $25^{\circ} \mathrm{C}$. (A) $0.1 \mathrm{mM}$ luteolin, $0.5 \mathrm{mM} \mathrm{H}_{2} \mathrm{O}_{2}$ and $1 \mu \mathrm{M}$ metAtHb3; (B) $0.1 \mathrm{mM}$ quercetin, $1 \mathrm{mM} \mathrm{H}_{2} \mathrm{O}_{2}$ and $2 \mu \mathrm{M}$ metAtHb1; (C) $0.1 \mathrm{mM}$ resveratrol, $1 \mathrm{mM} \mathrm{H}_{2} \mathrm{O}_{2}$ and $2 \mu \mathrm{M}$ metAtHb2; (D) $0.1 \mathrm{mM}$ epicatechin, $1 \mathrm{mM} \mathrm{H}_{2} \mathrm{O}_{2}$ and $2 \mu \mathrm{M}$ metAtHb1; 
The flavanols epicatechin (Figure1D) and the catechin (spectra not shown) from our investigation are the only phenolic compounds in which the product of the reaction is characterized with formation and appearing of band with maximum absorbance in the visible region, at $412 \mathrm{~nm}$, instead of the typical decay of the starting bands which was the case for the others investigated phenolic compounds. The reason for this may be the formation of a more stable epicatechin/catechin based radical generated during the reaction or a dimer/trimer oxidize form that have an extended aromatic structure which leads to absorbances at higher wavelengths, but further investigation and employing of other techniques (such as EPR, NMR, chromatography) would be necessary. In addition, other tested compounds exhibit no reaction such as vanilic and gallic acid, most probably due to too high redox potential compared to the ferryl redox potential.

One may expect that the ferryl abstracts one electron from the phenolic compound, generating an unstable transient radical-based species that may further be oxidized either enzymatically or by interacting with other radicals leading to stable quinone forms or dimers or multimeric species, however, little influence is expected from $\mathrm{Hb}$ to another since they are expected to behave similarly. However, in some cases, the fact that the product/s of the reaction may be different form the type of used $\mathrm{Hb}$ appears very interesting (catechin and epicatechin, Figure $2 A B$ ).

A further comparison between the starting and the end point spectra in the reaction of some compounds with the three phytoglobins (AtHb1, AtHb2 and $A t H b 3$ ) in the presence of $\mathrm{H}_{2} \mathrm{O}_{2}$ is shown on Figure 2. In all cases (shown in Figure 2) the oxidation of the phenolic compounds in the presence of $\mathrm{AtHb} 3$ is the least completed, probably due to the high sensitivity of this truncated hemoglobin towards $\mathrm{H}_{2} \mathrm{O}_{2}$, in which case the highly reactive ferryl species are generated very fast with far smaller peroxide amounts (data not shown), so in the presence of higher peroxide concentration degradation of the hemoglobin occurs. Besides other aspect that may influence the end reaction spectrum (the intensity rather than the profile) is the completion of the reaction (the $\mathrm{Hbs}$ have different stability in the working condition and high peroxide concentration), the small different features may be explained by the rate of the monoelectronic abstraction, shape and size of the binding pocket which could lead to slight different transient species with different fate. 


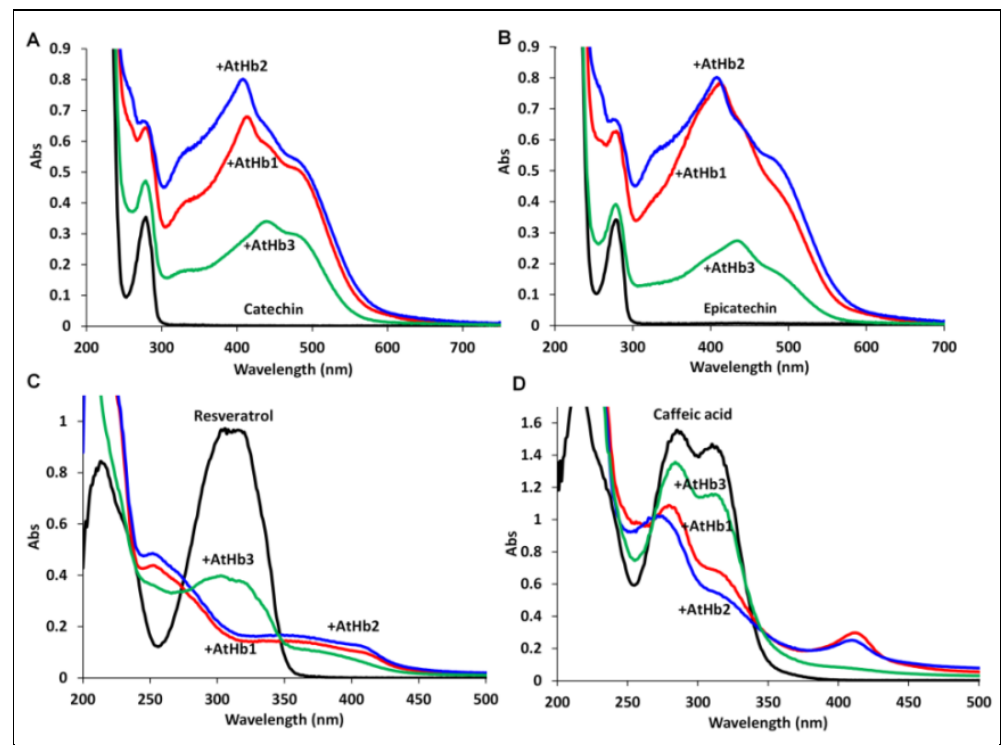

Figure 2. Characteristic UV-Vis spectra (A) $0.1 \mathrm{mM}$ catechin; (B) $0.1 \mathrm{mM}$ epicatechin; (C) $0.1 \mathrm{mM}$ resveratrol; (D) $0.1 \mathrm{mM}$ caffeic acid in the presence and absence of the AtHb1, AtHb2 and AtHb3

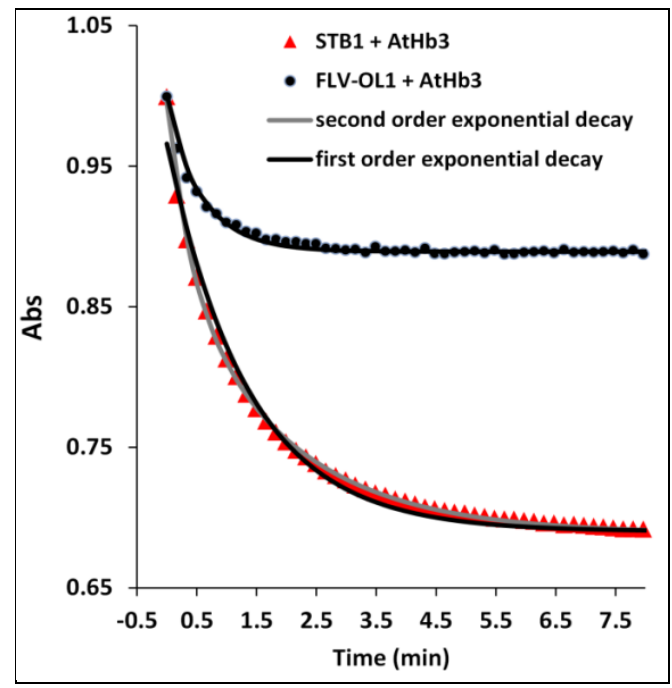

Figure 3. Kinetic traces for the oxidation of resveratrol (STB1) and quercetin (FLVOL1), both in presence of AtHb3 and peroxide exhibiting different decay profiles, resveratrol requiring second order exponential decay model $\left(R^{2}=0.999\right)$ while for quercetin first order exponential decay being sufficed $\left(R^{2}=0.995\right)$. 
The kinetic profiles of the phenolics oxidation (absorbance change in time) follow either a first order or second order exponential decay described by the equation 1 (where $t$ refers to time, $t 1$ and $t 2$ are the time constants and A1,2 are amplitude relating constants) and are compound specific, in a similar fashion with the reaction between the artificial radical DPPH and phenolic compounds (Figure 3) [45]. This could be a good indication for the complexity of the reaction; reactions that follow a fist order exponential decay profile suggest a direct oxidation of the substrate to a single oxidized product. Second order exponential decay trend may indicate either two types of generated radicals with similar but different end products or enzymatic independent generation of secondary radicals that might at their turn lead to different oxidized products. Furthermore, this is not only substrate specific but also globin specific, for example the two studied glycosides follow a second order exponential decay profile for $\mathrm{AtHb} 1$ and AtHb3 but a monoexponential curve for AtHb2 while the opposite is valid for caffeic acid (HYDCN1) (see Table 2 for all data regarding this aspect).

Table 2. Time constants $t_{1}$ and $t_{2}$ and the half-life $t_{1 / 2}$ for the oxidation of the studied compounds in presence of peroxide and the three Hbs. The slash in the $t_{2}$ columns indicates that first order decay suffice to fit the data.

\begin{tabular}{|c|c|c|c|c|c|c|c|c|c|c|}
\hline & \multirow{2}{*}{ Code Name } & \multicolumn{3}{|c|}{ AtHb1 } & \multicolumn{3}{|c|}{ AtHb2 } & \multicolumn{3}{|c|}{ AtHb3 } \\
\hline & & $t_{1}$ & $t_{2}$ & $t_{1 / 2}$ & $t_{1}$ & $t_{2}$ & $t_{1 / 2}$ & $t_{1}$ & $t_{2}$ & $t_{1 / 2}$ \\
\hline 1 & FLV-ON1 & $\begin{array}{c}0.52 \pm \\
0.04\end{array}$ & $\begin{array}{c}3.80 \pm \\
0.03\end{array}$ & $\begin{array}{l}0.46 \pm \\
0.003\end{array}$ & $\begin{array}{c}0.71 \pm \\
0.08\end{array}$ & $\begin{array}{c}12.52 \pm \\
0.35\end{array}$ & $\begin{array}{c}0.67 \pm \\
0.06\end{array}$ & $\begin{array}{l}0.32 \pm \\
0.007\end{array}$ & I & $\begin{array}{l}0.22 \pm \\
0.005\end{array}$ \\
\hline 2 & FLV-ON2 & $\begin{array}{c}9.19 \pm \\
0.51 \\
\end{array}$ & I & $\begin{array}{c}6.37 \pm \\
0.35 \\
\end{array}$ & $\begin{array}{c}2.67 \pm \\
0.35 \\
\end{array}$ & $\begin{array}{c}10.46 \pm \\
0.83\end{array}$ & $\begin{array}{c}2.13 \pm \\
0.24 \\
\end{array}$ & $\begin{array}{c}0.8 \pm 0 \\
.17\end{array}$ & $\begin{array}{l}23.27 \\
\pm 7.47 \\
\end{array}$ & $\begin{array}{l}0.77 \pm \\
0.17 \\
\end{array}$ \\
\hline 3 & FLV-OL1 & $\begin{array}{c}1.34 \pm \\
0.02\end{array}$ & $\begin{array}{r}15.45 \\
\pm 0.08\end{array}$ & $\begin{array}{l}1.23 \pm \\
0.019\end{array}$ & $\begin{array}{c}1.29 \pm \\
0.17\end{array}$ & $\begin{array}{c}21.16 \pm \\
0.50\end{array}$ & $\begin{array}{l}1.22 \pm \\
0.13\end{array}$ & $\begin{array}{l}0.43 \pm \\
0.004\end{array}$ & 1 & $\begin{array}{l}0.30 \pm \\
0.003\end{array}$ \\
\hline 4 & GLY1 & $\begin{array}{c}2.35 \pm \\
0.05\end{array}$ & $\begin{array}{c}9.10 \pm \\
0.25\end{array}$ & $\begin{array}{c}1.87 \pm \\
0.04\end{array}$ & $\begin{array}{r}10.73 \\
\pm 0.04\end{array}$ & l & $\begin{array}{c}7.44 \pm \\
0.03\end{array}$ & $\begin{array}{c}0.43 \pm \\
0.02\end{array}$ & $\begin{array}{c}2.89 \pm \\
0.28\end{array}$ & $\begin{array}{l}0.38 \pm \\
0.017\end{array}$ \\
\hline 5 & GLY2 & $\begin{array}{c}2.53 \pm \\
0.11 \\
\end{array}$ & $\begin{array}{c}9.51 \pm \\
0.33 \\
\end{array}$ & $\begin{array}{c}1.99 \pm \\
0.08 \\
\end{array}$ & $\begin{array}{r}11.85 \\
\pm 0.05 \\
\end{array}$ & l & $\begin{array}{c}8.12 \pm \\
0.03 \\
\end{array}$ & $\begin{array}{c}0.53 \pm \\
0.05 \\
\end{array}$ & $\begin{array}{c}1.34 \pm \\
0.12 \\
\end{array}$ & $\begin{array}{c}0.38 \pm \\
0.03 \\
\end{array}$ \\
\hline 6 & FLV-3-OL1 & $\begin{array}{l}1.03 \pm \\
0.016\end{array}$ & $\begin{array}{c}4.66 \pm \\
0.09\end{array}$ & $\begin{array}{c}0.84 \pm \\
0.14\end{array}$ & $\begin{array}{c}3.18 \pm \\
0.04\end{array}$ & $\begin{array}{c}13.85 \pm \\
0.13\end{array}$ & $\begin{array}{c}2.58 \pm \\
0.03\end{array}$ & $\begin{array}{c}0.197 \\
\pm 0.00 \\
1\end{array}$ & $\begin{array}{l}0.98 \pm \\
0.013\end{array}$ & $\begin{array}{l}0.16 \pm \\
0.001\end{array}$ \\
\hline 7 & FLV-3-OL2 & $\begin{array}{l}1.10 \pm \\
0.016\end{array}$ & $\begin{array}{c}4.74 \pm \\
0.1\end{array}$ & $\begin{array}{l}0.89 \pm \\
0.014\end{array}$ & $\begin{array}{c}3.49 \pm \\
0.13\end{array}$ & $\begin{array}{c}10.28 \pm \\
0.21\end{array}$ & $\begin{array}{c}2.61 \pm \\
0.08\end{array}$ & $\begin{array}{l}0.33 \pm \\
0.004\end{array}$ & $\begin{array}{c}1.27 \pm \\
0.03\end{array}$ & $\begin{array}{l}0.27 \pm \\
0.003\end{array}$ \\
\hline 8 & VAL & & & & eaction & the pres & th cond & & & \\
\hline 9 & HYDCN1 & $\begin{array}{c}2.01 \pm \\
0.02 \\
\end{array}$ & I & $\begin{array}{l}1.39 \pm \\
0.016\end{array}$ & $\begin{array}{c}6.85 \pm \\
0.22 \\
\end{array}$ & $\begin{array}{c}22.72 \pm \\
1.6 \\
\end{array}$ & $\begin{array}{c}5.27 \pm \\
0.19 \\
\end{array}$ & $\begin{array}{l}1.27 \pm \\
0.02 \\
\end{array}$ & 1 & $\begin{array}{l}0.88 \pm \\
0.014 \\
\end{array}$ \\
\hline 10 & HYDCN2 & $\begin{array}{c}0.62 \pm \\
0.02 \\
\end{array}$ & $\begin{array}{c}6.80 \pm \\
0.06 \\
\end{array}$ & $\begin{array}{l}0.57 \pm \\
0.018\end{array}$ & $\begin{array}{r}12.87 \\
\pm 0.22 \\
\end{array}$ & l & $\begin{array}{c}8.92 \pm \\
0.15 \\
\end{array}$ & $\begin{array}{c}0.77 \pm \\
0.15 \\
\end{array}$ & $\begin{array}{c}2.97 \pm \\
0.22 \\
\end{array}$ & $\begin{array}{c}0.61 \pm \\
0.09 \\
\end{array}$ \\
\hline 11 & HYDCN3 & $\begin{array}{c}0.26 \pm \\
0.01\end{array}$ & $\begin{array}{c}7.21 \pm \\
0.15\end{array}$ & $\begin{array}{l}0.25 \pm \\
0.009\end{array}$ & $\begin{array}{c}6.75 \pm \\
0.13\end{array}$ & I & $\begin{array}{c}4.68 \pm \\
0.09\end{array}$ & $\begin{array}{c}1.63 \pm \\
0.05\end{array}$ & I & $\begin{array}{l}1.13 \pm \\
0.035\end{array}$ \\
\hline 12 & COUM1 & $\begin{array}{c}5.88 \pm \\
0.12\end{array}$ & l & $\begin{array}{l}4.08 \pm \\
0.008\end{array}$ & $\begin{array}{r}67.91 \\
\pm 0.95 \\
\end{array}$ & I & $\begin{array}{r}47.07 \\
\pm 0.66 \\
\end{array}$ & $\begin{array}{l}0.38 \pm \\
0.013\end{array}$ & I & $\begin{array}{c}0.27 \pm \\
0.09\end{array}$ \\
\hline 13 & STB1 & $\begin{array}{l}1.82 \pm \\
0.007\end{array}$ & I & $\begin{array}{l}1.26 \pm \\
0.005\end{array}$ & $\begin{array}{c}1.65 \pm \\
0.05\end{array}$ & I & $\begin{array}{c}1.15 \pm \\
0.04\end{array}$ & $\begin{array}{l}0.37 \pm \\
0.017\end{array}$ & $\begin{array}{c}1.84 \pm \\
0.03\end{array}$ & $\begin{array}{c}0.31 \pm \\
0.01\end{array}$ \\
\hline
\end{tabular}


This data further supports the fact that these enzymes do not only influence the rate of the reaction but also the enzymatic mechanism.

$$
A b s_{t}=A b s_{0}+A 1 e^{\frac{-t}{t 1}}+A 2 e^{\frac{-t}{t 2}}
$$

Regarding the rate of the reaction, the time constants $t_{1}$ and $t_{2}$ and the half-lives $t_{1 / 2}$ for the investigated phenolic compounds are presented in Table 2. The calculated values for the $t_{1 / 2}$ in the case of AtHb3 are lowest, ranging in the interval of $0.16-1.13 \mathrm{~min}$ for catechin and $p$-coumaric acid, respectively, indicating very fast reactions. The highest are in the case of AtHb2 in the interval of 0.67-8.92 min; for luteolin and ferulic acid, respectively with exception of aesculetin with value of $47.07 \mathrm{~min}$, thus this globin is a poor catalyst for type of reaction while the AtHb1 sets in between the two.

In order to easily evaluate simultaneously the profile, rate and the yield of the reaction (also influenced by enzyme stability), graphical representation of the reaction product percentage, at three stages are shown in Figure 4.

PCA based mapping allows evaluation of the similarities or lack thereof between the studied compounds, based on their kinetic profiles using the three different globins as enzymes (Figure 5). Poor grouping based on structural similarities is observed (especially for AtHb1) but notably again highly different mapping exists from enzyme to enzyme. In case of AtHb2 and AtHb3, a weak but visible grouping of the compounds, based on their structural similarities, is noticed.

A better grouping of the compounds, in good agreement with their structural details (Table 1 ) is observed if cluster analysis is employed upon the kinetic parameters (Figure 6). Once more, the compound grouping was enzyme specific. In case of Athb1, two major clusters were obtained, one consisting of the flavonoids (with the exception of flavan-3-ols) and another including all the others while in the case of the other two enzymes, one compound was very different from the rest (aesculetin in case of AtHb2, very poor reaction and apigenin for AtHb3, very fast reaction with AtHb3); all the others were grouping in three small groups with more or less structural similarities (Figure 6). In addition, the correlation circle of the variables obtained after PCA application upon the kinetic parameters suggests that the $t_{1 / 2}$ is mainly determined by the $t_{1}$ component and the rates were in the following order: AtHb2, AtHb1 and AtHb3, in good agreement with their peroxidase activity while the amplitude of the percentage of the oxidized reaction product is in reverse order as expected from the data presented in Figure 4. 
PROBING REDUCING POWER FOR FERRYL PHYTOGLOBINS OF SEVERAL ...

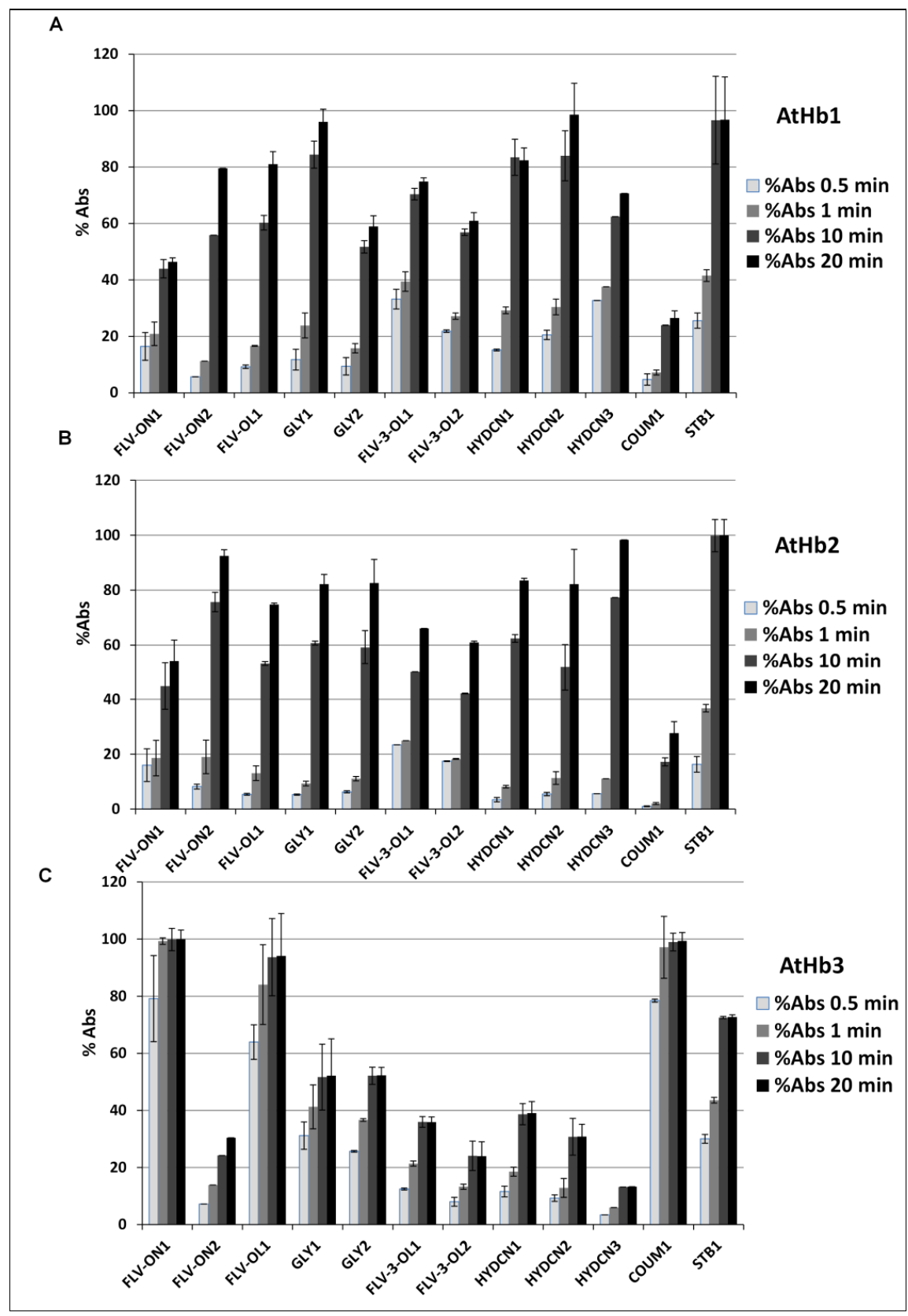

Figure 4. Percentage of oxidized phenolics monitored at the $\lambda_{\max }$ in presence of (A) metAtHb1 (B) metAtHb2 and (C) metAtHb3 after $0.5 \mathrm{~min}, 1 \mathrm{~min}, 10 \mathrm{~min}$ and $20 \mathrm{~min}$ reaction time (error bars represent standard deviations of the mean). 

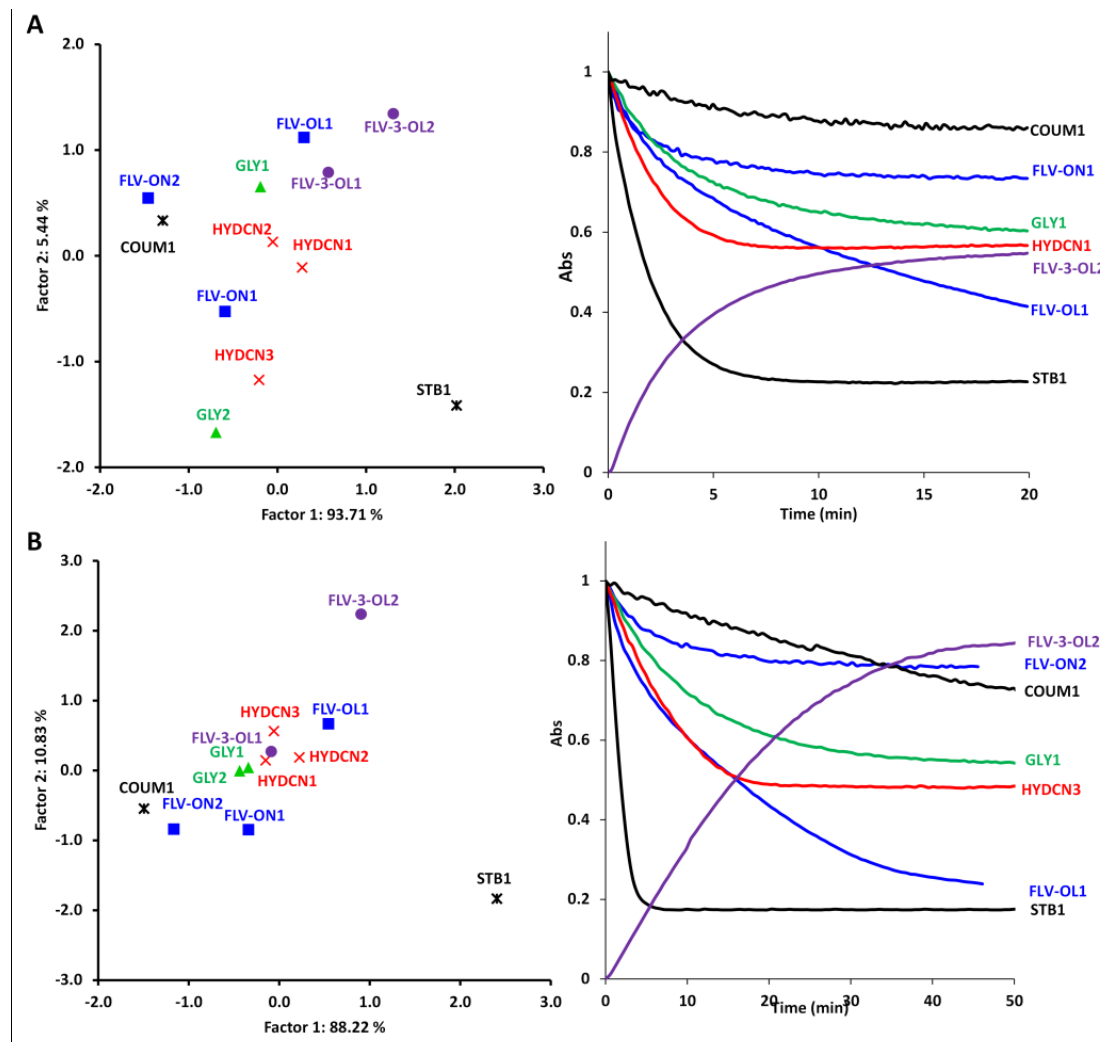

C
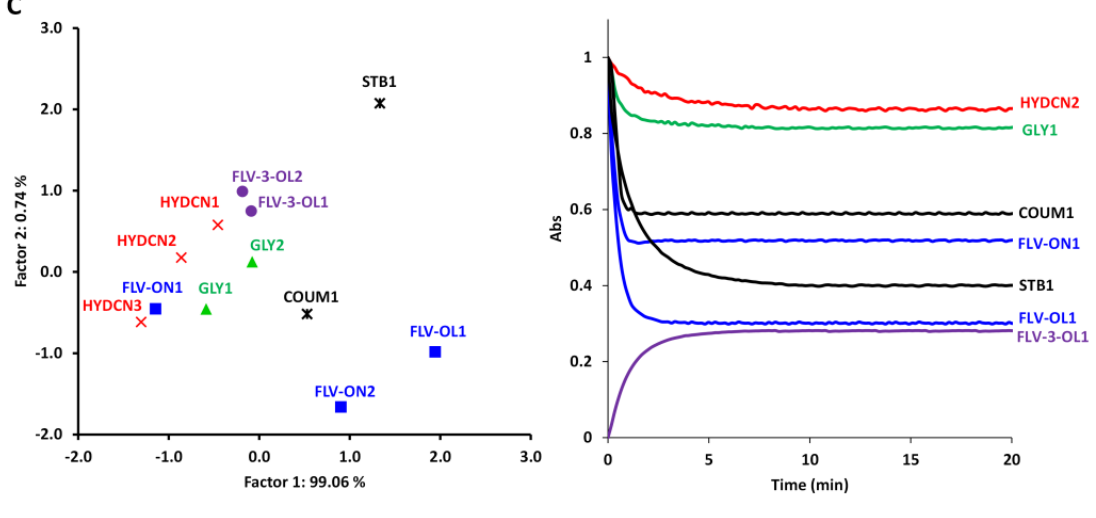

Figure 5. PCA based mapping of the studied compounds using the entire kinetic profiles for the reactions between $0.1 \mathrm{mM}$ phenolic compound in presence of peroxide and (A) metAtHb1, (B) metAtHb2, (C) metAtHb3. On the right, the kinetic profiles of some representatives from different classes are shown. Color codes are consistent with Tables 1 and 2. 

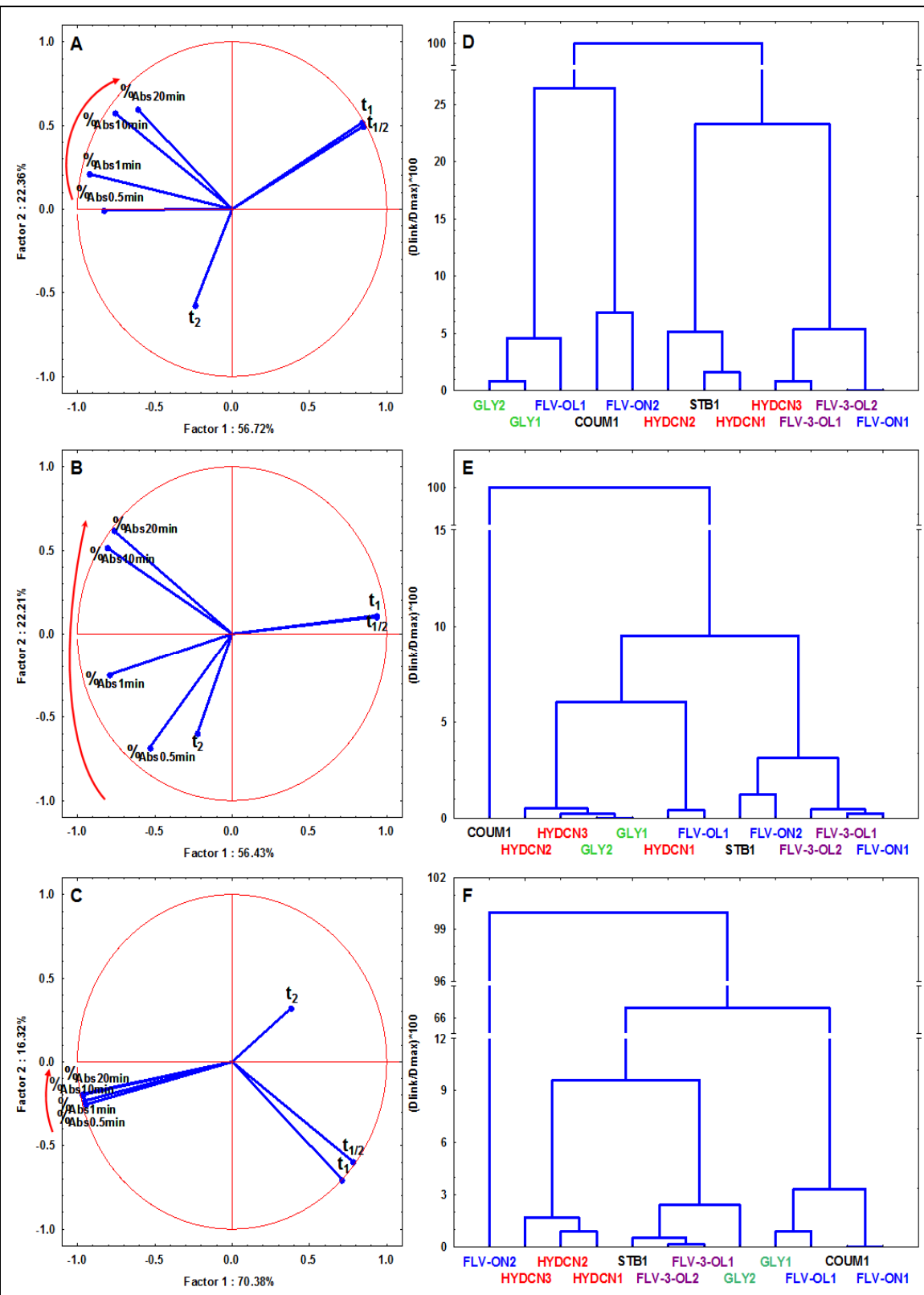

Figure 6. Correlation circle of the variables after PCA applying upon the kinetic and yields of the reactions for the three enzymes $\mathrm{A}$. AtHb1, B. AtHb2, C. AtHb3 and the clustering results obtained through cluster analysis on the same data (Ward's method, distance measure: 1-Pearson r), D. AtHb1, E. AtHb2, F. AtHb3. 
Coupling the profiles analysis, their PCA mapping and cluster analysis, one may observe that the presence of a 3-hydroxyl group in the heterocyclic $\mathrm{C}$ ring at flavonoids (quercetin) increases the reducing power of the compounds, while the substitution with additional hydroxyl or methoxyl groups at positions 3 , 5 and 7 of rings $A$ and $C$ seem to be less important. Glycosylation of 3hydroxyl group in ring $\mathrm{C}$, such as at rutin, quercitrin or isoquercitrin, reduces significantly the reducing power, most probably due to steric hindrance. This is in good agreement with other biochemical or the electrochemical activity of the flavonoids that they depend on the chemical structure and the moieties orientation in the molecule [44].

\section{CONCLUSIONS}

To conclude, a set of thirteen phenolic compounds were comparatively analysed for their reducing power for ferryl forms of the three $A$. thaliana non symbiotic hemoglobins. The kinetic profiles of their oxidation processes were analysed using PCA and cluster analysis and it was found that the three globins are different not only in terms of rate but also in terms of mechanism, thus, the reducing power of the studied compounds is strongly enzyme specific with weak accuracy to be predicted solely from their chemical structure.

\section{EXPERIMENTAL SECTION}

\section{Materials and methods}

Quercetin, rutin, quercetin, isoquercitrin, caffeic acid, ferulic acid, $p$ coumaric acid, vanillic acid, hydrogen peroxide $\left(\mathrm{H}_{2} \mathrm{O}_{2}\right)$ and methanol were purchased from Sigma-Aldrich (Steinheim, Germany). Luteolin, apigenin, $(+)$-catechin, (-)-epicatechin, aesculetin, and resveratrol were obtained from Fluka (Buchs, Switzerland). The stock solutions of the phenolic compounds were prepared by dissolving the compound in methanol.

The three recombinant Arabidopsis thaliana non-symbiotic plant hemoglobins (AtHb1, AtHb2 and AtHb3), each belonging to a different class of phytoglobins were expressed in E. coli BL21 (DE3) as follows: E.coli cells containing the expression vector were grown at $37^{\circ} \mathrm{C}$ and $190 \mathrm{rpm}$ in LB medium and $100 \mathrm{mg} / \mathrm{L}$ ampicillin until the $\mathrm{OD}_{600}$ reached $0.6-0.8$ (for $\mathrm{AtHb} 1$ and $\mathrm{AtHb} 2$ ) followed by temperature decreasing to $25^{\circ} \mathrm{C}$, then 0.3 $\mathrm{mM}$ hemin and $0.25 \mathrm{mM}$ isopropyl $\beta$-d-1-thiogalactopyranoside (IPTG) were 
added. For AtHb3, the cells were grown at $37^{\circ} \mathrm{C}$ and $190 \mathrm{rpm}$ in $\mathrm{LB}$ medium supplemented with $100 \mathrm{mg} / \mathrm{L}$ ampicillin until the $\mathrm{OD}_{600}$ reached $1.1-1.2$, then, the temperature was reduced to $28^{\circ} \mathrm{C}$ and $0.1 \mathrm{mM}$ ferrous ammonium sulfate, $0.25 \mathrm{mM} 5$-aminolevulinic acid and $0.3 \mathrm{mM} \mathrm{IPTG}$ was added to the culture flask. Additionally, $40 \mathrm{~mL}$ LB medium saturated with $\mathrm{CO}$ by purging CO gas directly into the LB medium for approximately 20 min, was added before the flask was sealed. [46] The cells were incubated overnight at $25^{\circ} \mathrm{C}$ (for $\mathrm{AtHb} 1$ and $\mathrm{AtHb} 2$ ) and $28^{\circ} \mathrm{C}$ for AtHb3 at $110 \mathrm{rpm}$. Cells were harvested by centrifugation ( $4000 \mathrm{rpm}$ for $20 \mathrm{~min}$ at $4^{\circ} \mathrm{C}$ ), resuspended in $100 \mathrm{~mL}$ lysis buffer pH 7.8 (300 mM NaCl, 50 mM Na $2 \mathrm{HPO}_{4}$ ), previously purged with $\mathrm{CO}$ gas for $15 \mathrm{~min}$ in case of $\mathrm{AtHb}$. The cells were sonicated on ice, in the presence of $1 \mathrm{mM}$ phenylmethanesulfonyl fluoride. The lysate was centrifuged (16000 rpm for $45 \mathrm{~min}$ at $4^{\circ} \mathrm{C}$ ) and the hemoglobin containing supernatant was purified using Ni-NTA-agarose affinity resin (GE Healthcare), MBPTrap HP columns (GE Healthcare) and size exclusion chromatography.

The spectrophotometric data were acquired using Varian Cary® 50 UV-Vis Spectrophotometer equipped with temperature - controlled multi cell holder using $1 \mathrm{~cm}$ quartz cuvette.

The reducing power of thirteen phenolic compounds towards the three plant hemoglobins (ferric $\mathrm{Hb}, \mathrm{Fe}^{+}-\mathrm{Hb}$ ) in $50 \mathrm{mM}$ phosphate buffer $\left(\mathrm{Na}_{2} \mathrm{HPO}_{4}\right), \mathrm{pH} 7.4$ and temperature of $25^{\circ} \mathrm{C}$ was investigated. For this purpose $0.1 \mathrm{mM}$ of each phenolic substrate was transferred into a $1 \mathrm{~mL}$ quartz cuvette, followed by addition of $2 \mu \mathrm{M} \mathrm{AtHb} 1$; shortly after $1 \mathrm{mM} \mathrm{H}_{2} \mathrm{O}_{2}$ was added and the reaction was monitored by continuously acquiring UV-Vis spectra between 200 and $800 \mathrm{~nm}$. The same procedure, under the same conditions, was done for each phenolic substrate, only using $2 \mu \mathrm{M} \mathrm{AtHb2}$; while in the case of AtHb3 $0.1 \mathrm{mM}$ of each phenolic substrate was mixed with $1 \mu \mathrm{M} \mathrm{AtHb3}$, followed by addition of $0.5 \mathrm{mM} \mathrm{H}_{2} \mathrm{O}_{2}$. All experiments were done in duplicates. The traces extracted at the maximum absorption wavelength in time were fitted in Origin 6.1 using the function for exponential decay with first or second order, with exception of FLV-3-OL1 and 2 which showed hyperbolical increasing of the absorbance in time, so the values of the absorption were transformed into exponential decay. Following the kinetic profile of the reactions, $\tau$ (time constant of the decay quantity) was estimated and using the following equation, accordingly: $t_{1 / 2}=\tau \times \ln 2$ (reactions following exponential decay with first order) and $t_{1 / 2}=\frac{\tau_{1} \times \tau_{2}}{\tau_{1}+\tau_{2}}$ (reactions following exponential decay with second order), $t_{1 / 2}$ (the total half-life) was calculated; the results are shown in Table2. For statistical evaluation, principal component analysis and cluster analysis, Statistica 8 (Stat. Soft Inc., USA) was used. 


\section{ACKNOWLEDGMENTS}

Financial support from the Romanian National Authority for Scientific Research and Innovation (CNCS - UEFISCDI, project PN-II-RU-TE-2014-42555 ) is gratefully acknowledged.

\section{REFERENCES}

1. M. De L. R. Giada, "Oxidative Stress and Chronic Degenerative Diseases - A Role for Antioxidants", InTech, Rijeka, Croatia, 2013, chapter 4.

2. K.G. Ramawat, J.M. Mérillon, "Natural Products: Phytochemistry, Botany and Metabolism of Alkaloids, Phenolics and Terpenes", Springer, 2013, chapter 6.

3. D. Lin, M.Xiao, J. Zhao, Z.Li, B. Xing, X. Li, Q. Zhang, Y. Liu, H. Chen, W. Qin, H. Wu, S. Chen, Molecules, 2016, 21, 1374.

4. N. Balasundram, K. Sundram, S. Samman, Food Chemistry, 2006, 99, 131-203.

5. P.G. Pietta, Journal of Natural Products, 2000, 63, 1035-1042.

6. S. Amalesh, G. Das, K.S. Das, International Journal of Pharmacy Sci Tech, 2011, 6, 12-35.

7. V. Cheynier, Phytochemistry Reviews, 2012, 11, 153-177.

8. J. Treml, K. Šmejkal, Comprehensive Reviewsin Food Science and Food Safety, 2016, 15, 720-738.

9. S. Kumar, A.K. Pandey, The ScientificWorld Journal, 2013, 2013, 16.

10. G. Agati, M. Tattini, New Phytologist, 2010, 186, 786-793.

11. G. Agati, E. Azzarello, S. Pollastri, M. Tattini, Plant Science, 2012, 196, 67-76.

12. R.J. Nijveldt, E.V. Nood, D. EC. V. Hoorn, K.V. Norren, P. AM. V. Leewen, The American Journal of Clinical Nutrition, 2001, 74, 418-425.

13. W.Y. Huang, Y.Z. Cai, Y. Zhang, Nutrition and Cancer, 2010, 62, 1-20.

14. C. Rivière, A.D. Pawlus, J. M. Mérillon, Natural Product Reports, 2012, 29, 13171333.

15. K.N. Venugopala, V. Rashmi, B. Odhav, BioMed Research International, 2013, 2013, 14-19.

16. A.V. Rao, L.G. Rao, "Phytochemicals Isolation, Characterisation and Role in Human Health", AvE4EvA, InTech, 2015, chapter 5.

17. K.E. Heim, A.R. Tagliaferro, D.J. Bobilya, The Journal of Nutritional Biochemistry, 2002, 13, 572-584

18. B. Sciences, B.G.- Hospital, Biochemical Pharmacology, 1992, 43, 1167-1179,

19. J. Xi R. Guo, International Journal of Biological Macromolecules, 2007, 40, 305-311.

20. K. Weng, S. Mat-junit, A. Ismail, N. Aminudin, A. Abdul-aziz, Food Chemistry, 2014, 146, 85-93. 
21. M.F. V.N. Arroyo-Currás, ECS transactions, 2010, 29, 349-359.

22. E.S. Gil, R.O. Couto, Revista Brasileira de Farmacognosia, Brazilian Journal of Pharmacognosy, 2013, 23, 542-558.

23. N. Wijayanti, N. Katz, S. Immenschuh, Current Medicinal Chemistry, 2004, 11, 981-986.

24. A. Sakamotoa, S. Sakuraob, K. Fukunagab, T. Matsubarac, M. Ueda-Hashimotoa, S. Tsukamotoa, M. Takahashia, H. Morikawa, FEBS Letters, 2004, 572, 27-32.

25. M. Delledonne, Y. Xia, R.A. Dixon, C. Lamb, Nature, 1998, 394, 585-588.

26. M. Tiso, J. Tejero, C. Kenney, S. Frizzell, M.T. Gladwin, Biochemistry, 2012, 51, 5285-5292.

27. Gautam Sarath, 3 Jean-Louis Hilbert,4 Richard A. Watts,5,6 Elizabeth S. Dennis, 5 W. James Peacock, B. J. Smagghe, J.A. Hoy, R. Percifield, S. Kundu, M.S. Hargrove, G. Sarath, J. Hilbert, R.A. Watts, E.S. Dennis, W.J. Peacock, S. Dewilde, L. Moens, G.C. Blouin, J.S. Olson, C.A. Appleby, Biopolymers, 2009, 91, 1083-1096.

28. V.G. Villegas, S.K. Gopalasubramaniam, R.A. Peter, Gene, 2007, 398, 78-85.

29. J.A. Hoy, H. Robinson, J.T. Trent, S. Kakar, B.J. Smagghe, M.S. Hargrove, Journal of Molecular Biology, 2007, 371, 168-179.

30. J. Tejero, M.T. Gladwin, Biological Chemistry, 2014, 395, 631-639.

31. Y. Wang, X. Barbeau, A. Bilimoria, P. Lagüe, M. Couture, J.K.H. Tang, PLoS One, 2015, 10, 1-30.

32. A. Lama, S. Pawaria, K.L. Dikshit, FEBS Letters, 2006, 580, 4031-4041.

33. R. Silaghi-Dumitrescu, B.J. Reeder, P. Nicholls, C.E. Cooper, M.T. Wilson, Biochemical Journal, 2007, 395, 391-395.

34. N. Lu, Y. Ding, Z. Yang, P. Gao, International Journal of Biological Macromolecules, 2016, 89, 175-180.

35. L. Gebicka, E. Banasiak, Acta Biochimica Polonica, 2009, 56, 509-513.

36. A.I. Alayash, R.P. Patel, R.E. Cashon, Antioxidants \& Redox Signaling, 2001, 3, 313-327.

37. A.C. Moţ, C. Coman, C. Miron, G. Damian, C. Sarbu, R. Silaghi-Dumitrescu, Food Chemistry, 2014, 143, 214-222.

38. N. Lu, P. Chen, Q. Yang, Y. Peng, Toxicology in Vitro, 2011, 25, 833-838.

39. J. Yuan, H. Liu, X. Kang, Z. Lv, G. Zou, Journal of Molecular Structure, 2008, 891, 333-339.

40. Y. Jia, A. I. Alayash, Free Radical Biology \& Medicine, 2008, 45, 659-666.

41. S. Chakrabortya, S. Chaudhurib, B. Paharib, J. Taylorc, P. K. Senguptab, B. Senguptac, Journal of Luminescence, 2013, 132, 1522-1528.

42. R. Gabbianelli, M. Santroni, D. Fedeli, Kantar, G. Falcioni, Biochemical and Biophysical Research Communications, 1998, 242, 560-564.

43. Y.S. Tarahovsky, Y.A. Kim, E.A. Yagolnik, E.N. Muzafarov, BBA Biomembranes, 2014, 1838, 1235-1246.

44. L.H. Yao, Y.M. Jiang, J. Sji, F.A. Tomás-Barberán, N. Datta, R. Singanusong, S.S. Chen, Plant Foods for Human Nutrition, 2004, 59, 113-122. 
45. A.C. Moț, R. Silaghi-Dumitrescu, C. Sârbu, Journal of Food Composition and Analysis, 2011, 24, 516-522.

46. B.J. Reeder and M.A. Hough, Acta Crystallographica Section D, 2014, D70, 14111418. 